\title{
Ketotifen and Cardiovascular Risk in Patients with Type 2 Diabetes Mellitus
}

\author{
Sahar M El-Haggar ${ }^{1}$, Wael F Farrag ${ }^{2}$ and Fedaa A Kotkata ${ }^{1 *}$ \\ ${ }^{1}$ Clinical Pharmacy Department, Faculty of Pharmacy, Tanta University, Egypt \\ ${ }^{2}$ Internal Medicine Department, Faculty of Medicine, Tanta University, Egypt \\ *Corresponding author: Kotkata FA, Assistant lecturer of Clinical Pharmacy, Clinical Pharmacy Department, Faculty of Pharmacy, Tanta University, \\ Egypt, Tel: 002 01017872669; Fax: 002 0403335466; E-mail: Fedaa.eldeep@yahoo.com
}

Received date: Nov 11, 2016; Accepted Date: Jan 10, 2017; Pubished date: Jan 14, 2017

Copyright: (c) 2017 El-Haggar SM, et al. This is an open-access article distributed under the terms of the Creative Commons Attribution License, which permits unrestricted use, distribution, and reproduction in any medium, provided the original author and source are credited.

Citation: Kotkata FA, Farrag WF, El-Haggar S M ( 2017) Ketotifen an d Cardiovascular Ri sk in Patients wit h Typ e 2 Diabetes Mel litus. J Cli n Mol Endocrinol 2: 1

\section{Abstract}

Objective: Mast cells found to be an important contributor to inflammation, obesity, diabetes and atherosclerosis. We evaluate the ability of ketotifen to reduce cardiovascular risk in patient with type 2 diabetes millets (T2DM).

Method: In a randomized controlled study we recruited forty eight patients with T2DM from Internal Medicine Department at Tanta University Hospital, Egypt. They were classified in to three groups. Group 1: received glimepiride (GL) $3 \mathrm{mg} /$ day alone; group 2: received $\mathrm{GL} 3 \mathrm{mg} /$ day +ketotifen $1 \mathrm{mg}$ once daily; group 3: received GL $3 \mathrm{mg} /$ day +ketotifen $1 \mathrm{mg}$ twice daily. Fasting blood samples were obtained before and 12 weeks after treatment for biochemical analysis of IL-6 and lipid profile with subsequent calculation of Castelli index 1 and atherogenic coefficient. Body mass index was also calculated for all patients. Data were analyzed by paired student's t-test and one way analysis of variance, $p<0.05$ was considered statistically significant.

Results: The obtained data suggested that ketotifen in its twice daily dose significantly improves lipid profile and decreases IL-6 level, castelli index 1 and atherogenic coefficient.

Conclusions: Mast cell stabilization with ketotifen can decrease the risk of diabetes associated cardiovascular complications

Keywords: T2DM; Mast Cells; Ketotifen; obesity; Cardiovascular Risk

\section{Introduction}

Patients with DM will present with microvascular or macrovascular degeneration [1]. The morbidity and mortality associated with macrovascular degeneration far outweigh the risks of microvasular complications in older people with diabetes [2]. Macrovascular disease denotes arterial diseases, in particular the coronary arteries and the arteries supplying the brain and the feet. Degeneration of these vessels involves the build-up of fatty substances (cholesterol), which leads to atherosclerosis [3].

Heart disease and stroke represent approximately $65 \%$ to $85 \%$ of diabetes-related mortality. Therefore, patients with have a significantly increased risk of coronary heart disease, cerebrovascular disease (stroke), or peripheral arterial disease, compared to those without T2DM [4]. Obesity increases the risk of cardiovascular disease in adults and has been strongly associated with IR in normoglycemic persons and in individuals with T2DM $[5,6]$. Mast cells (MCs) are important inflammatory cells that participate in immune responses during allergic reactions. Former studies, however, suggest that these cells also participate in other inflammatory diseases, such as cancers, inflammatory bowel disease, metabolic bone disease, renal injury, arthritis, atherosclerosis, abdominal aortic aneurysms, obesity, and diabetes [7].

ketotifen is a relatively selective, noncompetitive antagonist of histamine $\mathrm{H} 1$ receptors and is a mast cell stabilizer, inhibiting the release of inflammatory mediators from mast cells [8]. The most important finding of recent studies is that mast cell stabilization with cromolyn or ketotifen reduces body weight gain and improves glucose and insulin tolerance in mice without noticeable toxicity [7]. No clear data was reported upon the effect of mast cell stabilizers on human, so the present study was designed to investigate the ability of ketotifen to decrease cardiovascular risk (CV) in patients with T2DM.

\section{Patients and Methods}

\section{Patients}

We recruited forty eight patients with T2DM from internal medicine department at Tanta University Hospital, Egypt. The inclusion criteria were: diabetes duration less than 10 years, treated with glimepiride and age ranged from 45 to 55 years. The exclusion criteria were patients who had any other inflammatory disease (bone, asthma, etc.), severe hepatic or renal disease, epilepsy and also pregnant or lactating females. 


\section{Study design}

A total number of 48 patients fulfilled the selection criteria were enrolled in the study. The study has been approved by the national research ethics committee (Tanta University ethical committee) and has been performed in accordance with the ethical standards as laid down in the 1964 declaration of Helsinki and its later amendments or comparable ethical standards. An informed written consent was obtained from all patients included in the study. The study design was parallel randomized controlled study to compare the effect of two different doses (once and twice daily) of ketotifen (Ketoti ${ }^{\circledR}$, Pharco, Egypt) in addition to glimepiride (GL) (Amaryl ${ }^{\circledR}$, SanofiAventis, Berlin, Germany). The patients were divided into three groups (each group [ $n=16]$ ) as following, group 1: received glimepiride (GL) $3 \mathrm{mg} / \mathrm{d}$ alone; group 2: received GL $3 \mathrm{mg} / \mathrm{d}$ plus ketotifen $1 \mathrm{mg}$ once daily and group 3: received GL $3 \mathrm{mg} / \mathrm{d}$ plus ketotifen $1 \mathrm{mg}$ twice daily for 12 weeks. All blood samples were obtained after a 12 hours fasting period. Blood samples were collected in tubes contain EDTA and centrifuged immediately. Plasma was separated, coded and stored at $-80^{\circ} \mathrm{C}$ until analysis.

\section{Demographic characters}

Patients' medical history was taken to ensure absence of any interacting or interfering drugs. Demographic data were collected at baseline using questionnaire. Information collected included age, sex, diabetes duration and BMI (Table 1).

Table 1: Demographic data of patients at baseline.

\begin{tabular}{|l|l|l|l|}
\hline Characteristics & (Group 1) & (Group 2) & (Group 3) \\
\hline Number & 16 & 16 & $3 / 13$ \\
\hline Sex (M/F) & $3 / 13$ & $50.1 \pm 4.6$ & $4 / 12$ \\
\hline Age (years) & $51.3 \pm 4.5$ & $7.1 \pm 2.7$ & $8.1 \pm 4.9$ \\
\hline Diabetes duration & $7.9 \pm 2.5$ & $37.5 \pm 6.1$ & $37.8 \pm 5.3$ \\
\hline BMl (kg/m $\mathrm{m}^{2}$ ) & $37.3 \pm 5.4$ & 3.5 \\
\hline
\end{tabular}

Data presented as mean \pm SD, Group 1: obese patients with type 2 diabetes treated with glimepiride 3 mg/d alone, (Group 2): obese patients with type 2 diabetes treated with glimepiride $3 \mathrm{mg} / \mathrm{d}$ plus ketotifen $1 \mathrm{mg}$ once daily, (Group 3): obese patients with type 2 diabetes treated with glimepiride $3 \mathrm{mg} / \mathrm{d}$ plus ketotifen $1 \mathrm{mg}$ twice daily; M: Male; F: Female; BMI: Body Mass Index.

\section{Anthropometric evaluations}

Weights were measured and recorded to the nearest $0.5 \mathrm{~kg}$. Body heights were measured and recorded to the nearest centimeter. Body mass index was calculated which is defined as the weight in kilograms divided by the square of the height in meters i.e. $B M I=$ weight $(\mathrm{kg}) /$ hight $^{2}(\mathrm{~m})$. Height and weight were measured using Detecto scale (Detecto Company, 203 East Daugherty Sheet, USA).

\section{Biochemical assays}

Lipid panel: Plasma was used for determination of lipid profiles including total cholesterol (TC) which was measured by enzymatic colorimetric method [9], triglycerides (TGs) which was measured by enzymatic- colorimetric method [10] and High density lipoprotein (HDL-C) which was determined by precipitation method [11] using commercial kits (BioMed, Germany). Low-density lipoprotein cholesterol (LDL-C) was calculated using friedewald formula, where LDL-C $=[T C-H D L-C-$ (TGs/5)] provided that TGs level is less than $400 \mathrm{mg} / \mathrm{dl}$ [12].

Assay of interleukin-6 (IL-6): Enzyme-linked immunosorbent assay (ELISA) using commercial kits was carried out according to manufacturers' instructions for assay of plasma IL-6 Platinum ELISA (eBioscience, San Diego).

\section{Atherogenic ratios}

The Atherogenic ratios were calculated as follows:

Castelli's Risk Index (CRI-I)=TC/HDLC
Atherogenic Coefficient $(\mathrm{AC})=(\mathrm{TC}-\mathrm{HDLC}) / \mathrm{HDLC}$

\section{Statistical analysis}

Data were analyzed using SPSS statistical package version 20.0, IBM corporation software group, 2011, USA. Paired student's t-test was used to assess any significant difference between each group at baseline and after 12 weeks of treatment course. One way analysis of variance (ANOVA) test followed by bonferroni or tamhane tests were used to assess any significant difference among the three groups at base line and after 12 weeks. Values were presented as mean \pm standard deviation (SD). All $p$ values were two-tailed and $p<0.05$ was considered significant for statistical analysis.

\section{Results}

\section{Characteristics of patients}

At baseline, there were no significant differences between (group 1) received glimepiride alone and intervention groups (group 2 and group 3 ) received glimepiride plus ketotifen once and twice daily respectively, in demographic or anthropometric parameters (Table 1).

\section{Effect of ketotifen on BMI, lipid profile and IL-6}

A summary of the mean \pm SD values of variables at baseline and after 12 weeks in all groups are presented in (Table 2). After 12 weeks of co-treatment with glimepiride plus ketotifen $1 \mathrm{mg}$ 
twice daily (group 3), there were significant decrease in $\mathrm{BMI}$, IL-6, TC, TGs and LDL-C, While there was significant increase in HDL-C. For group 1 who receive glimepiride alone there were no significant difference in these outcome variables measured over the intervention period, While regarding group 2 who receive glimepiride plus ketotifen once daily there was only decrease in IL-6 level. The comparison of the three groups before and 12 weeks after treatment revealed that, there were no significant differences in measured parameters between all groups at baseline. After 12 weeks, Comparing group 3 with 1 there was significant decrease in IL-6 $(P<0.01)$, TGs $(P<0.05)$, and increase in HDL-C $(P<0.05)$. Comparing group 2 with group 1 there was significant decrease in TGs $(P<0.05)$ and IL-6 $(P<0.01)$. Comparing group 3 with 2 there was significant increase in HDL$C(P<0.01)$.

Table 2: Clinical variables at baseline and after 12 weeks in the three groups.

\begin{tabular}{|c|c|c|c|c|c|c|}
\hline \multirow[b]{3}{*}{ Variables } & \multicolumn{2}{|l|}{ (Group 1) } & \multicolumn{2}{|l|}{ (Group 2) } & \multicolumn{2}{|l|}{ (Group 3) } \\
\hline & \multicolumn{2}{|l|}{$n=16$} & \multicolumn{2}{|l|}{$n=16$} & \multicolumn{2}{|l|}{$n=16$} \\
\hline & Baseline & 12 weeks & Baseline & 12 weeks & Baseline & 12 weeks \\
\hline $\mathrm{BMI}\left(\mathrm{kg} / \mathrm{m}^{2}\right)$ & $37.3 \pm 5.4$ & $37.6 \pm 5.3$ & $37.5 \pm 6.1$ & $37.6 \pm 5.8$ & $37.8 \pm 5.3$ & $37.2 \pm 5.9^{*}$ \\
\hline $\mathrm{TC}(\mathrm{mg} / \mathrm{dl})$ & $140.2 \pm 20.7$ & $147.8 \pm 25$ & $151.7 \pm 30.1$ & $146.4 \pm 31.1$ & $146.7 \pm 29.9$ & $129.3 \pm 28.3^{* *}$ \\
\hline $\mathrm{TC}(\mathrm{mmol} / \mathrm{l})$ & $3.6 \pm 0.54$ & $8.7 \pm 0.65$ & $3.9 \pm 0.78$ & $3.8 \pm 0.8$ & $3.8 \pm 0.77$ & $3.3 \pm 0.73^{* *}$ \\
\hline TGs (mg/dl) & $123.2 \pm 20.1$ & $127.8 \pm 22.1$ & $105.5 \pm 30$ & $97.3 \pm 31.1 b$ & $116.1 \pm 42.6$ & $97 \pm 38.4^{* *} a$ \\
\hline TGs (mmol/l) & $1.4 \pm 0.23$ & $1.5 \pm 0.25$ & $1.2 \pm 0.34$ & $1.1 \pm 0.35 b$ & $1.3 \pm 0.49$ & $1.1 \pm 0.44^{* *} a$ \\
\hline HDL-C (mg/dl) & $32.4 \pm 6.6$ & $31.9 \pm 8.1$ & $30.3 \pm 2.7$ & $31.2 \pm 4.3$ & $30.9 \pm 4$ & $38.5 \pm 3.9^{\star *} a$ \\
\hline HDL-C (mmol/l) & $0.84 \pm 0.17$ & $0.83 \pm 0.2$ & $0.78 \pm 0.07$ & $0.81 \pm 0.11$ & $0.8 \pm 0.1$ & $0.99 \pm 0.1^{* *} a$ \\
\hline LDL-C (mg/dl) & $83.1 \pm 17.2$ & $87.8 \pm 28.2$ & $100.3 \pm 27.4$ & $95.8 \pm 28.7$ & $92.8 \pm 32.8$ & $71.26 \pm 27.9^{* *}$ \\
\hline LDL-C (mmol/l) & $2.2 \pm 0.45$ & $2.3 \pm 0.73$ & $2.6 \pm 0.71$ & $2.5 \pm 0.74$ & $2.4 \pm 0.85$ & $1.9 \pm 0.72^{\star \star}$ \\
\hline IL-6 (pg/ml) & $2.9 \pm 0.9$ & $3.2 \pm 1.2$ & $2.6 \pm 0.8$ & $2.1 \pm 0.7^{*} \mathrm{c}$ & $2.8 \pm 0.7$ & $2.1 \pm 0.8^{* *} a$ \\
\hline
\end{tabular}

Data presented as mean \pm SD, Group 1: obese patients with type 2 diabetes treated with glimepiride 3 mg/d alone, (Group 2): obese patients with type 2 diabetes treated with glimepiride $3 \mathrm{mg} / \mathrm{d}$ plus ketotifen $1 \mathrm{mg}$ once daily, (Group 3): obese patients with type 2diabetes treated with glimepiride $3 \mathrm{mg} / \mathrm{d}$ plus ketotifen $1 \mathrm{mg}$ twice daily. BMl: Body Mass Index; HDL-C: High Density Lipoprotein, IL-6: interleukin-6, LDL-C: low density lipoprotein; TC: Total Cholesterol; TGs: Triglycerides, * $\mathrm{p}<0.05$; ${ }^{*} \mathrm{p}<0.01$, compared with baseline values (paired sample t-test), a comparing group 3 with group 1; b comparing group 2 with group 1 , c comparing group 2 with group 1 .

\section{Effect of ketotifen on atherogenic ratios (CRI-1 and} $\mathrm{AC})$

A summary of the mean \pm SD values of CRI-1 and $A C$ at baseline and 12 weeks after in all groups are presented in (Table 3). After 12 weeks of co-treatment with glimepiride plus ketotifen twice daily (group 3), there were significant decrease in both CRI-1 and AC. While regarding group 1 and group 2 there were no significant changes in these ratios over the intervention period.
The comparison of the three groups before and 12 weeks after treatment revealed that, there were no significant differences in these ratios between all groups at baseline. After 12 weeks, comparing group 3 with 1 there were significant decrease in $\mathrm{CRI}-1$ and $\mathrm{AC}(\mathrm{P}<0.01)$. Comparing group 3 with 2 there was significant decrease in $C R I-1$ and $A C \quad(P<0.01)$. Comparing group 2 with 1 there was no significant difference (P>0.05).

Table 3: Atherogenic ratios at baseline and after 12 weeks in the three groups.

\begin{tabular}{|c|c|c|c|c|c|c|}
\hline \multirow[t]{3}{*}{ Ratios } & \multicolumn{2}{|l|}{ (Group 1) } & \multicolumn{2}{|l|}{ (Group 2) } & \multicolumn{2}{|l|}{ (Group 3) } \\
\hline & \multicolumn{2}{|l|}{$n=16$} & \multicolumn{2}{|l|}{$n=16$} & \multicolumn{2}{|l|}{$n=16$} \\
\hline & Baseline & 12 weeks & Baseline & 12 weeks & Baseline & 12 weeks \\
\hline CRI-1 & $4.4 \pm 0.74$ & $4.9 \pm 1.3$ & $4.99 \pm 0.79$ & $7.4 \pm 0.88$ & $4.8 \pm 1.3$ & $3.4 \pm 0.78^{* *} a b$ \\
\hline$A C$ & $3.4 \pm 0.7$ & $3.8 \pm 1.3$ & $3.9 \pm 0.8$ & $3.7 \pm 0.9$ & $3.8 \pm 1.2$ & $2.4 \pm 0.8^{* *} a b$ \\
\hline \multicolumn{7}{|c|}{$\begin{array}{l}\text { Data presented as mean } \pm \mathrm{SD} \text {, Group } 1 \text { : obese patients with type } 2 \text { diabetes treated with glimepiride } 3 \text { mg/d alone, (Group } 2 \text { ): obese patients with type } 2 \text { diabetes treated } \\
\text { with glimepiride } 3 \mathrm{mg} / \mathrm{d} \text { plus ketotifen } 1 \mathrm{mg} \text { once daily, (Group } 3 \text { ): obese patients with type } 2 \text { diabetes treated with glimepiride } 3 \mathrm{mg} / \mathrm{d} \text { plus ketotifen } 1 \mathrm{mg} \text { twice daily. } \\
\mathrm{CRI}-1 \text { : Castelli Risk Index } 1 \text {; AC: Atherogenic Coefficient, }{ }^{* *} \mathrm{p}<0.01 \text {, compared with baseline values (paired sample t-test), a comparing group } 3 \text { with group } 1 \text {; b comparing } \\
\text { group } 3 \text { with group } 2 \text {. }\end{array}$} \\
\hline
\end{tabular}




\section{Discussion}

In individuals with type 2 DM cardiovascular (CV) risk is increased by a clustering of risk factors such as abdominal obesity, impaired fasting glucose, increased blood pressure, low HDL-C, increased TG, and an increase in small, dense LDL particles. The current increase in the incidence of type $2 \mathrm{DM}$ in the population perhaps poses the most urgent CV risk [13]. The present study evaluate whether the prescribed mast cell stabilizer (ketotifen) could decrease CV risk in patients with T2DM.

The results obtained from group 3 in which patients received glimepiride plus ketotifen twice daily, revealed a significant reduction in body mass index (BMI) compared to patients' baseline values. While compared to the other groups there was no significant difference. Former preclinical studies supporte the ability of ketotifen to decrease weight [14-16], while other studies on human showed that ketotifen induce weight gain [17-19]. So, the effect of ketotifen on weight is controversial and this may be due to different mechanisms at different doses [20] or difference in metabolic pathway between animal and human [15]. In human themselves there may be many factors that can influence this effect such as race, genetic polymorphism or comorbidities. Therefore, further studies are needed to investigate the exact effect of ketotifen on weight and which factors can influence this effect.

Elevated serum levels of LDL-C and TGs and low level of HDL-C are strongly associated with increased risk for macrovascular events (e.g., myocardial infarction, ischemic stroke, and coronary mortality) among patients with T2DM [21-23]. It is beneficial to treat any or all components of the lipid beyond LDL-C alone, in order to most optimally reduce morbidity and mortality in patients with diabetes. Former study confirmed the hypothesis that independently achieving HDL-C, TGs and nonHDL-C goals can lead to significant reduction in microvascular complications risk irrespective of LDL-C goal attainment [24].

The obtained results indicated that receiving ketotifen twice daily in group 3 significantly decreased TC, TGs, LDL-C and increased HDL-C compared to patients' baseline values. However, comparing this group to group 1 there was a significant decrease in TGs and significant increase in HDL-C. The observed decrease in LDL-C and TGs is consistent with result achieved in rats with T2DM treated with ketotifen [15]. Our results seem matched with the observed decrease in TGs, LDL-C and increase in HDL-C in mice with atherogenesis treated with another MC stabilizer "cromolyn" [25].

Interleukin-6 (IL-6) is inflammatory mediator produced by macrophages in the adipose tissue [26]. It's one of mast cell cytokine mediators $[7,27]$. This cytokine is increased in obesity and has multiple effects on insulin sensitivity in muscles, liver, or beta cells of the pancreas, ultimately leading to insulin resistance [26]. Our results showed that treatment with glimepiride plus ketotifen twice daily reverse obesity-related increases in IL-6 in obese patients with T2DM. This effect is consistent with the result obtained from obese mice with T2DM [14] and rats with T2DM [15].
Different combinations of these lipid profile parameters can be used to identify such high risk individuals. Castelli Risk Index (CRI) and Atherogenic Coefficient (AC) are the two ratios studied in predicting the risk of coronary artery disease. These are the calculated fractions which can be used in the clinical setting for assessing the risk of cardiovascular disease beyond the routinely done lipid profile. Calculating certain ratios using these parameters especially in situations where LDL-C levels are below target range may increase the identification of at-risk individuals [28].

The result of this study revealed that group 3 received ketotifen twice daily showed a significant decrease in CRI-1 below 4 and $A C$ below 3 . This result proves the ability of ketotifen in its twice daily dose to decrease CVD risk in patients with diabetes.

The limitations of this study are lacking of measurement of other useful parameters such as HOMA-IR and cardiac markers.

\section{Conclusion}

Mast cell stabilization with ketotifen can decrease the risk of cardiovascular complications in type 2 diabetes patients through improving atherogenic ratios.

\section{Acknowledgements}

The authors sincerely appreciate Doctor Tarek M. Mostafa, Assistant Professor of Clinical Pharmacy, Tanta University, for his role in this paper.

\section{Conflict of interest}

There are no conflicts of interest.

\section{References}

Winters S, Jernigan V (2000) Vascular disease risk markers in diabetes: monitoring \& intervention. Nurse Pract 25: 40-65.

2. Wallace JI (1999) Management of diabetes in elderly. Clin Diabetes 17:1-19.

Nair M (2007) Diabetes mellitus, part 1: physiology and complications. Br J Nurs 16: 184-188.

4. Jellinger PS, Smith DA, Mehta AE, Ganda O, Handelsman Y, et al. American Association of Clinical Endocrinologists' Guidelines for Management of Dyslipidemia and Prevention of Atherosclerosis. Endocr Pract. 18:1-78.

Bonadonna RC, Groop L, Kraemer N, Ferrannini E, Del Prato S, et al. (1990) Obesity and insulin resistance in humans: a doseresponse study. Metabolism 39: 452-459.

6. Rexrode KM, Manson JE, Hennekens CH (1996) Obesity and cardiovascular disease. Curr Opin Cardiol 11: 490-495.

Wang J, Shi GP (2011) Mast cell stabilization: novel medication for obesity and diabetes. Diabetes Metab Res Rev 27: 919-924.

8. Greiner JV, Mundorf T, Dubiner H, Lonsdale J, Casey R, et al. (2003) Efficacy and safety of ketotifen fumarate $0.025 \%$ in the conjunctival antigen challenge model of ocular allergic conjunctivitis. Am J Ophthalmol. 136: 1097-1105. 
9. Watson $D$ (1960) A simple method for the determination of serum cholesterol. Clin Chim Acta. 5: 637-643.

10. Fossati P, Prencipe L (1982) Serum triglycerides determined colorimetrically with an enzyme that produces hydrogen peroxide. Clin Chem. 28: 2077-2080.

11. Warnick GR, Wood PD (1995) National Cholesterol Education Program recommendations for measurement of high-density lipoprotein cholesterol: executive summary. The National Cholesterol Education Program Working Group on lipoprotein measurement. Clin Chem. 41: 1427-1433.

12. Friedewald WT, Levy RI, Fredrickson DS (1972) Estimation of the concentration of low-density lipoprotein cholesterol in plasma, without use of the preparative ultracentrifuge. Clin Chem. 18 : 499-502.

13. Koleva DI, Andreeva-gateva PA, Orbetzova MM, Atanassova IB (2015) Atherogenic Index of Plasma, Castelli Risk Indexes and Leptin / Adiponectin Ratio in Women with Metabolic Syndrome. Int J Pharm Med Res. 6: 12-18.

14. Liu J, Divoux A, Sun J, Zhang J, Clément K, et al. (2009) Genetic deficiency and pharmacological stabilization of mast cells reduce diet-induced obesity and diabetes in mice. Nat Med. 15: 940-945.

15. Chen FQ, Wang J, Liu XB, Ma XY, Zhang XB, et al. (2013) Levels of inflammatory cytokines in type 2 diabetes patients with different urinary albumin excretion rates and their correlation with clinical variables. J Diabetes Res. 138969

16. Habibi As B, Vaez H, Imankhah T, Hamidi S (2014) Impact of caffeine on weight changes due to ketotifen administration. Adv Pharm Bull 4: 83-89.

17. Ockenga J, Rohde F, Süttmann U, Herbarth L, Ballmaier $M$, et al. (1996) Ketotifen in HIV-infected patients: effects on body weight and release of TNF-alpha. Eur J Clin Pharmacol 50: 167-170.

18. Canny GJ, Reisman J, Levison H (1997) Does ketotifen have a steroid-sparing effect in childhood asthma? Eur Respir J 10: 65-70.
19. Tantichaiyakul P, Preutthipan A (2010) Ketotifen versus inhaled budesonide for controlling childhood asthma. J Med Assoc Thai 93: 541-549.

20. Nemati M, Habibi B, Sharifi K (2006). Effect of ketotifen and cyproheptadine on appetite and weight. Iran J Pharm Sci. 2:123128.

21. Misra A, Kumar S, Kishore VN, Kumar A (2003). The role of lipids in the development of diabetic microvascular complications: Implications for therapy. Am J Cardiovasc Drugs 3: 325-338.

22. Leiter LA (2005) The prevention of diabetic microvascular complications of diabetes: is there a role for lipid lowering? Diabetes Res Clin Pract 68 Suppl 2: S3-14.

23. Harris SB, Naqshbandi M, Bhattacharyya O, Hanley AJ, Esler JG, et al. (2011) Major gaps in diabetes clinical care among Canada's First Nations: results of the CIRCLE study. Diabetes Res Clin Pract 92: 272-279.

24. Toth PP, Simko RJ, Palli SR, Koselleck D, Quimbo RA, et al. (2012) The impact of serum lipids on risk for microangiopathy in patients with type 2 diabetes mellitus. Cardiovasc Diabetol 11: 109.

25. Wang J, Sjöberg S, Tia V, Secco B, Chen H, et al. (2013) Pharmaceutical stabilization of mast cells attenuates experimental atherogenesis in low-density lipoprotein receptor-deficient mice. Atherosclerosis $229: 304-309$.

26. Vrachnis N, Belitsos P, Sifakis S, Dafopoulos K, Siristatidis C, et al. (2012) Role of adipokines and other inflammatory mediators in gestational diabetes mellitus and previous gestational diabetes mellitus. Int J Endocrinol., 2012 :549748.

27. Zhang J, Shi GP (2012) Mast cells and metabolic syndrome. Biochim Biophys Acta 1822: 14-20.

28. Bhardwaj S, Bhattacharjee J, Bhatnagar MK, Tyagi, S, Delhi N, et al. (2013) Atherogenic index of plasma, castelli risk index and atherogenic coefficient- new parameters in assessing cardiovascular risk. Int J Pharm Biol Sci. 3: 359-364. 